\title{
Psychological Predictors of Intensive Practice of Massively Multiplayer Online Role-Playing Games
}

\author{
Jessica Marchetti, Carol Sankey, Isabelle Varescon \\ Université Sorbonne Paris Cité, Boulogne-Billancourt, France
}

\begin{abstract}
Massively Multiplayer Online Role-Playing Games (MMORPG) are video games with special characteristics, which are a persistent immersive online virtual world with the creation of an avatar and an important social aspect. These specificities raise the question of the need for some players to practice intensively and to neglect the real world in favor of the virtual one. The aim of this study was to determine predictive factors for intensive practice of MMORPG. 313 regular MMORPG adult players were recruited on specialized forums. They completed several questionnaires: Beck Depression Inventory, Spielberger Inventory of State-Trait Anxiety, Rosenberg Self-Esteem Scale, Life Satisfaction Scale, Interpersonal Relationships Quality Scale, Feeling of Social Belonging Scale, and Problem Video Game Playing Questionnaire and Internet Addiction Test to assess the intensity of practice. Hierarchical multiple regression analysis highlighted that intensive practice of MMORPG can be significantly predicted by the age of the player $(b=-0.134)$, depressive symptoms $(b=0.313)$ and feeling of social belonging $(b$ $=-0.186$ ). These results highlighted the link between intrapersonal (anxiety, depressive symptoms, self-esteem, life satisfaction) and interpersonal (quality of relationships, feeling of social belonging) difficulties and the intensity of practice of MMORPG.
\end{abstract}

Keywords: online, video games, intensive practice, adult gamers, psychosocial variables

\section{Introduction}

Massively Multiplayers Online Role Playing Games (MMORPG) are video games that require an Internet connection and have the distinctive feature to combine at the same time a large number of players in the same persistent and immersive virtual world. Players are represented by a virtual character, or avatar, which is actually a virtual identity they create from scratch (physical characteristics and personality) and who will be able to evolve (Griffiths, Davies, \& Chappell, 2004; Wan \& Chiou, 2006).

Several studies have attempted to highlight the variables that could be predictive of intensive use of online video games. There seems to be a link between the age of the players and the intensity of their practice: the younger the players, the more intensely they play online video games (Griffiths et al., 2004; Caplan, Williams, $\&$ Yee, 2009). Self-esteem has received little attention in relation to the use of online video games. However, it

Jessica Marchetti, Ph.D. student, Laboratory of Psychopathology and Health Processes, Institut Universitaire de Psychologie Paris Descartes, Université Sorbonne Paris Cité.

Carol Sankey, Postdoctoral researcher, Laboratory of Psychopathology and Health Processes, Institut Universitaire de Psychologie Paris Descartes, Université Sorbonne Paris Cité.

Isabelle Varescon, Professor, Director of the Laboratory of Psychopathology and Health Processes, Institut Universitaire de Psychologie Paris Descartes, Université Sorbonne Paris Cité. 
has been shown that a low self-esteem predicts problematic use (Ko, Yen, Chen, Chen, \& Yen, 2005; Lemmens, Valkenburg, \& Peter, 2011). A high level of anxiety and depressive symptoms have been observed in people with problematic use of online games (Whang, Lee, \& Chang, 2003; Caplan et al., 2009; Longman, O'Connor, \& Obst, 2009; Mentzoni et al., 2011; Scott \& Porter-Armstrong, 2013). A decrease of psychological well-being and daily life satisfaction among players with excessive practice have also been demonstrated (Ko, et al., 2005; Mentzoni et al., 2011; Kowert, Vogelgesang, Festl, \& Quandt, 2015).

Online video games encourage exchanges between the players by developing virtual socialization, thanks to specialized discussion forums (Cole \& Griffiths, 2007). This social aspect which is present in MMORPG, makes intensive practice of these games different from that of offline games (Lo, Wang, \& Fang, 2005). Online players would be or would have the feeling of being in trouble in their relationships to others (Longman et al., 2009). The game would be an escape from this reality and allow them to counter their feelings of personal worthlessness, nonrecognition and loneliness (Wan \& Chiou, 2006). Thus, for intensive online gamers, replacing the real by the virtual would be the only conceivable way of life, the online universe allowing them to express themselves in a way that is not possible in real life (Cole \& Griffiths, 2007). It would allow recognition by others and a sense of existence that are not present in real life. Hence, some authors have proposed that social interaction in the virtual world is a determining factor in motivating users to stay online for long periods (Ng \& Wiemer-Hastings, 2005).

However, various studies investigating players' interpersonal relationships show conflicting results. Notably, intensive online have few social relations or poor quality of social relations compared to other players (Lo et al., 2005; Longman et al., 2009). Other authors discuss the social potential of MMORPG and the positive effects of this type of game, by showing that many players create online friendships (Lo et al., 2005; Zhong, 2011). The game would satisfy a desire for interpersonal relationships (Ko et al., 2005; Williams, 2006).

Furthermore, although this virtual world can lead to isolation in real life and to a break with reality, online video games can be perceived by players as a means of socialization to overcome their loneliness and to feel part of an online network (Hsu, Wen, \& Wu, 2009; Martončik \& Lokša, 2016). For many players with an intensive practice of MMORPG, a kind of dependency will develop in particular with the strong feeling of affiliation with the virtual community that will affect their daily lives with a significant impact on their actual social life (Lo et al., 2005; Hsu et al., 2009). Online video games would respond to a search for social contact.

The objective of this study was to determine the predictive factors of intensive practice of MMORPG by investigating several psychosocial variables often involved in intensive practice of online video games: anxiety, depressive symptoms, self-esteem, life satisfaction, quality of interpersonal relationships and feeling of social belonging.

\section{Material and Methods}

\section{Participants and Procedure}

Participants had to be over 18 years old, speak and read French and play MMORPG daily.

Participants were recruited online on French forums (general online video games forums and specialized in MMORPG). After agreement of the forums' moderators, a message explaining the study with an URL towards questionnaires was posted. Before filling out the various scales, participants had access to the information letter and to the consent form, which they had to validate to participate to the study. Participants were informed of the goals and methods of the study. They were also informed that their involvement in the research was completely 
voluntary, that responses were anonymous and that they were free to withdraw at any time.

\section{Measures}

Sociodemographic characteristics and gaming. A sociodemographic data questionnaire was created to collect diverse information (gender, age, marital and professional status, level of education).

A questionnaire on the participants' gaming habits was also built to gather information about the gaming practice (online video games played, time spent playing, seniority of the practice).

Intensity of the gamers' practice. Given the absence of a test adapted in French for assessing online video games dependence, we chose two tools, among the most used in recent studies, to measure the intensity of the gamers' practice: the Internet Addiction Test (validated in French) and the Problem Video Game Playing Questionnaire (translated into French).

The Internet Addiction Test (IAT) (Young, 1998; Khazaal et al., 2008) is a self-report questionnaire which assesses cyberdependence and contains 20 items with answers on a Likert scale ranging from 0 to 5 . Frequent problems due to Internet use are found from a score of 50. Its internal consistency is high $(\alpha=0.87)$.

The Problem Video Game Playing Questionnaire (PVP) (Tejeiro \& Bersabé Moran, 2002; Bioulac, Arfi, Michel, \& Bouvard, 2010) is a self-administered questionnaire, based on diagnostic criteria of DSM-IV substance dependence and pathological gambling, which assesses the problems associated with the use of video games. It consists of 9 items, to which the subject must answer yes or no. The total score reflects the severity of the problems, but does not establish a diagnosis of addiction. This questionnaire was initially validated on an adolescent population (Tejeiro \& Bersabé Moran, 2002). Recently, Tejeiro, Espada, Gonzalvez, and Christiansen (2016) conducted a study validating the PVP on an adult population. The Cronbach's alpha was 0.58 .

An overall score was established to evaluate the intensity of game practice by adjusting the IAT and PVP scores and by adding them up ( $>50$ indicated an intensive practice of MMORPG).

Depressive symptoms. The Beck Depression Inventory (BDI-13) (Beck \& Beamesderfer, 1974; Bourque $\&$ Beaudette, 1982) is a self-report questionnaire consisting of 13 items evaluating the intensity of depressive symptoms. For each item, the subject must choose between four proposals with a score ranging from 0 to 3 . The total score ranges from 0 to 39. The internal consistency was high $(\alpha=0.85)$.

Anxiety. Gamers' anxiety was measured using the State-Trait Anxiety Inventory (STAI-Y) (Spielberger, 1983; Schweitzer \& Paulhan, 1990) which assesses both state anxiety and trait anxiety. This self-questionnaire consists of 20 items for each scale, and answers are listed on a Likert scale ranging from 1 to 4 . The total score therefore ranges from 20 to 80 . The Cronbach's alphas were 0.90 (trait anxiety) and 0.91 (state anxiety).

Self-esteem. Self-esteem was measured by the Rosenberg Self-Esteem Scale (RSES) (Rosenberg, 1965; Vallières \& Vallerand, 1990). It consists of 10 items in the form of statements, for which it is asked to position oneself to respond on a scale of four proposals ranging from "Strongly disagree" to "Strongly agree". The total score ranges from 10 to 40 . The internal consistency was high $(\alpha=0.90)$.

Life satisfaction. The Life Satisfaction Scale (LSS) (Diener, Emmons, Larsen, \& Griffin, 1985; Blais, Vallerand, Pelletier, \& Brière, 1989) is composed of 5 items for which the subject specifies the level of agreement on a 7 points Likert scale, ranging from "Strongly disagree" to "Strongly agree". The Cronbach's alpha was 0.90 .

Interpersonal relationships. The Interpersonal Relationships Quality Scale (IRQS) (Senécal, Vallerand, \& Vallières, 1992) consists of 4 statements measuring the quality of interpersonal relationships, for which the 
assessment is made on a Likert scale ranging from 0 to 4 points. This produces a score that ranges from 0 to 16 . The internal consistency was high $(\alpha=0.94)$.

Feeling of social belonging. The Feeling of Social Belonging Scale (FSBS) (Vallerand \& Richer, 1998) is composed of 10 items for which the subject specifies his level of agreement on a scale ranging from 1 ("Strongly disagree") to 7 ("Strongly agree"). The total score is between 10 and 70. The Cronbach's alpha was high (0.96).

\section{Data Analysis}

Data were analyzed using SPSS 22. In order to investigate the relationships between the variables studied and the intensity of practice of MMORPG, we performed correlations (Pearson correlation coefficient). Moreover, hierarchical multiple regression models were performed to meet the objective of this study.

\section{Results}

\section{Sociodemographic and Game Practice Data}

A total of 313 French MMORPG gamers completed the online questionnaires. The majority of participants were male $(85.4 \%)$. The age of participants ranged from 18 to 49 years $(M=26.95, S D=6.71)$. The majority of the participants were single (55.6\%) and employed (55.9\%). They reported they had been playing MMORPG for more than 5 years $(78.6 \%)$ and they played MMORPG more than 15 hours per week (56.2\%).

\section{Questionnaire Results}

The game practice intensity score (IAT and PVP) extended from 6 to $154(M=64.78, S D=30.99)$. A total of 136 players $(43.5 \%)$ were over the mean for the game practice intensity score.

Overall, participants were experiencing low levels of depressive symptoms $(M=3.62, S D=4.62)$ and low anxiety $(M=37.75, S D=10.65)$. Self-esteem $(M=33.39, S D=6.21)$, life satisfaction $(M=24.04, S D=6.73)$, quality of interpersonal relationships $(M=49.42, S D=15.53)$ and feeling of social belonging $(M=45.68, S D$ $=13.95$ ) were about average.

Table 1 gathers the descriptive analyses for all participants, and for players under ("no intensive practice") and over ("intensive practice ") the mean of the game practice intensity score.

Table 1

Scales Results and Sociodemographic Data

\begin{tabular}{lrrrrrr}
\hline & \multicolumn{3}{c}{ Total group $(n=313)$} & \multicolumn{2}{c}{ No intensive practice $(n=177)$} & \multicolumn{2}{c}{ Intensive practice $(n=136)$} \\
\cline { 2 - 6 } & Mean & \multicolumn{1}{c}{$S D$} & Mean & \multicolumn{1}{c}{$S D$} & Mean & \multicolumn{2}{c}{$S D$} \\
\hline Age & 26.95 & 6.71 & 28.09 & 6.82 & 25.46 & 11.21 \\
IAT & 36.96 & 14.81 & 27.53 & 9.299 & 49.24 & 1.43 \\
PVP & 2.50 & 1.74 & 1.37 & 0.91 & 3.98 & 21.92 \\
PVP/IAT & 64.78 & 30.99 & 42.76 & 14.59 & 93.42 & 5.64 \\
BDI & 3.62 & 4.62 & 2.07 & 2.82 & 5.63 & 11.35 \\
STAI & 37.75 & 10.65 & 34.53 & 8.84 & 41.94 & 7.14 \\
RSES & 33.39 & 6.21 & 34.99 & 4.83 & 31.31 & 7.15 \\
LSS & 24.04 & 6.73 & 25.66 & 5.91 & 21.94 & 16.47 \\
IRQS & 49.42 & 15.53 & 53.04 & 13.76 & 44.71 & 14.25 \\
FSBS & 45.68 & 13.95 & 49.56 & 12.43 & 40.64 & 14 \\
\hline
\end{tabular}

Notes. IAT: Internet Addiction Test; PVP: Problem Video Game Playing Questionnaire; PVP/IAT: Problem Video Game Playing Questionnaire / Internet Addiction Test; BDI: Beck Depression Inventory; STAI: State-Trait Anxiety Inventory; RSES: Rosenberg Self-Esteem Scale; LSS: Life Satisfaction Scale; IRQS: Interpersonal Relationships Quality Scale; FSBS: Feeling of Social Belonging Scale. 


\section{Relationship Between the Variables and the Intensity of Practice}

The intensity of game practice was positively correlated with depressive symptoms $(r=0.503, p<0.01)$ and anxiety $(r=0.445, p<0.01)$ : stronger depressive symptoms and higher anxiety were related to intensive game practice.

Moreover, significant negative correlations between the intensity of practice and self-esteem $(r=-0.456, p$ $<0.01)$, life satisfaction $(r=-0.407, p<0.01)$, quality of interpersonal relationships $(r=-0.373, p<0.01)$ and feeling of social belonging $(r=-0.375, p<0.01)$ were found.

Results of the relationship between the variables and the intensity of practice are summarized in Table 2.

Table 2

Correlations Between the Variables and the Intensity of MMORPG Practice (PVP/IAT Score)

\begin{tabular}{|c|c|c|c|c|c|c|}
\hline & STAI & BDI & RSES & LSS & IRQS & FSBS \\
\hline$\overline{\mathrm{PVP} / \mathrm{IAT}}$ & $0.445^{* * *}$ & $0.503^{* * *}$ & $-0.456^{* * *}$ & $-0.407^{* * *}$ & $-0.373^{* * * *}$ & $-0.375^{* * *}$ \\
\hline
\end{tabular}

Notes. ${ }^{\text {*** }} p<0.001$; PVP/IAT: Problem Video Game Playing Questionnaire / Internet Addiction Test; BDI: Beck Depression Inventory; STAI: State-Trait Anxiety Inventory; RSES: Rosenberg Self-Esteem Scale; LSS: Life Satisfaction Scale; IRQS: Interpersonal Relationships Quality Scale; FSBS: Feeling of Social Belonging Scale.

\section{Hierarchical Multiple Regression}

In order to investigate the predictive power of the variables studied on the intensity of game practice, we gathered them and performed a hierarchical multiple regression, with the score of intensity of practice as the dependent variable.

We conducted a hierarchical multiple regression in 3 steps. The first step allowed us to study the predictive power of age. The second stage focused on social variables (life satisfaction, quality of interpersonal relationships, feeling of social belonging). Finally, the third and last step allowed us to integrate the psychological variables (depressive symptoms, anxiety, self-esteem).

The results showed that age in the first step, explained $4.7 \%$ of the variance of the intensity of game practice $(F=16.425, p<0.001)$. When adding social variables, the model was significantly improved $(F=$ $23.384, p<0.001)$ and the independent variables explained $22.3 \%$ of the variance.

The final model accounted for a substantial amount of the variance in the dependent variable $(29.4 \%)$ when psychological variables were entered $(F=19.603, p<0.001)$. Results indicated that age $(b=-0.134, p=$ $0.007)$, depressive symptoms $(b=0.313, p<0.001)$ and feeling of social belonging $(b=-0.186, p=0.001)$ were all strong significant predictors of the intensity of game practice.

The results of this hierarchical regression are summarized in Table 3.

Table 3

Hierarchical Multiple Regression Analysis Predicting the Intensity of MMORPG Practice (PVP/IAT Score)

\begin{tabular}{lllll}
\hline Dependent variable & \multicolumn{5}{l}{ PVP/IAT } \\
\hline Independent variable & $\beta$ & Adj. $R^{2}$ & $F$ & Sig. \\
\hline Step 1 & & 0.047 & 16.425 & 0.000 \\
Age & $-0.224^{* * *}$ & & & \\
Step 2 & & 0.223 & 23.384 & 0.000 \\
LSS & -0.197 & & & \\
IRQS & -0.117 & & & \\
FSBS & $-0.206^{* * *}$ & & & \\
\hline
\end{tabular}


Table 3 to be continued

\begin{tabular}{lccc}
\hline Step 3 & $0.313^{* * *}$ & 0.294 & 0.000 \\
BDI & 0.151 & \\
STAI & 0.035 & \\
RSES & \multicolumn{1}{l}{. } & \\
\hline Notes. ${ }^{*} p<0.05,{ }^{* *} p<0.01,{ }^{* * * *} p<0.001 ;$ PVP/IAT: Problem Video Game Playing Questionnaire / Internet Addiction Test; BDI: \\
Beck Depression Inventory; STAI: State-Trait Anxiety Inventory; RSES: Rosenberg Self-Esteem Scale; LSS: Life Satisfaction \\
Scale; IRQS: Interpersonal Relationships Quality Scale; FSBS: Feeling of Social Belonging Scale.
\end{tabular}

\section{Discussion and Conclusion}

This study aimed to determine predictive factors of intensive practice of MMORPG in adult gamers.

The distinguishing feature of this study was the use of an overall score for measuring the intensity of game practice, using two questionnaires, the first assessing the use of Internet (IAT) and the second focusing on the game practice (PVP). This dual tool had the advantage of taking into account the two specificities of the online "world" and the context of the game.

We demonstrated that there is an association between intensive practice of MMORPG and some psychosocial characteristics of the players. The more a player plays, the more he would have a weak self-esteem, a low satisfaction of life, a poor quality of interpersonal relationships and a low sense of social belonging in real life. Although most studies that have focused on adolescents and young adults and have shown that these age categories have different characteristics from those of adults, our results are found in both adolescents (Ko et al., 2005; Lemmens et al., 2011) and adults (Hsu et al., 2009; Mentzoni et al., 2011).

In addition, our study showed that the more intensive the practice, the more players have a depressed mood and major anxiety. Our study's results were obtained with a measure of the intensity of online game practice, unlike what can be found in the literature, which either assesses Internet online practice or gaming practice, but not both (online gaming) (Whang et al., 2003; Caplan et al., 2009; Mentzoni et al., 2011).

Hierarchical multiple regression also showed the existence of several predictors in the model we proposed. Indeed, age, depressive symptoms and feelings of social belonging are strong predictors of the intensity of MMORPG practice. Thus, young players with depressive symptoms and a low feeling of social belonging are more likely to practice intensely MMORPGs. These results are reminiscent of the notion of refuge in the virtual proposed by some authors (Wan \& Chiou, 2006) that would allow players with difficulties in real life to invest an environment that suits them better. Nevertheless, low self-esteem, low life satisfaction and poor interpersonal relationships in real life do not seem to be predictive of excessive practice of online video games in our model. It thus contradicts the studies that state self-esteem, anxiety and quality of interpersonal relationships as explaining factors of this intensive practice (Ko et al., 2005; Lemmens et al., 2011; Mentzoni et al., 2011; Kowert et al., 2015). These conflicting results may be explained, at least partly, by the fact that our population was composed of adult participants with an average age of 26.95 years.

The character of our research is explorative and this study has limitations. First, the absence of consensus for a common assessment test to measure the intensity of practice made it difficult to compare our results with those of other studies, given the variety of tools used to measure the intensity of the practice of online video games (practice time, MINI, IAT, PVP, GAS). Second, this study was carried out online, which is also a limit in several respects. The obtained sample cannot be considered representative for all gamers of MMORPGs. 
Firstly, the tools used have been validated for paper use but not online. Furthermore, the award took place on the Internet and all participants were recruited on forums, which may create a bias in the answers that were given.

To conclude, our results highlighted the link between intrapersonal (anxiety, depressive symptoms, self-esteem, life satisfaction) and interpersonal (quality of relationships, feeling of social belonging) difficulties and the intensity of practice of MMORPG. In addition, some characteristics are predictive of the intensive use of MMORPG.

In the light of these results, future studies should focus on the characteristics that would predispose players to intensive practice based age and therefore investigate the reasons or motives that drive players to involve intensely in the virtual world by virtue of their personal characteristics.

Funding: This research was supported by grants from the Française des Jeux (FDJ), GIS Game and Society. The funding organization had no role in the design or conduct of the study; data collection, analysis, and interpretation; preparation, review and approval of the manuscript.

\section{References}

Beck, A. T., \& Beamesderfer, A. (1974). Assessment of depression: The depression inventory. In P. Pichot (Ed.), Modern problems in pharmacopsychiatry. Switzerland: Karger, Base.

Blais, M. R., Vallerand, R. J., Pelletier, L. G., \& Brière, N. M. (1989). L'Échelle de satisfaction de vie: Validation canadienne-française du "Satisfaction with Life Scale". Revue Canadienne des Sciences Comportementales, 21, 210-223.

Bioulac, S., Arfi, L., Michel, G., \& Bouvard, M. P. (2010). Intérêt de l'utilisation du questionnaire des problèmes associés aux jeux vidéo de Tejeiro (Problem Videogame Playing: PVP). Etude exploratoire chez des enfants présentant un TDA/H. Annales Médico Psychologiques, 168, 632-635.

Bourque, P., \& Beaudette, D. (1982). Etude psychométrique du questionnaire de dépression de Beck auprès d'un échantillon d'étudiants universitaires francophones. Revue Canadienne des Sciences Comportementales, 14(3), 211-218.

Caplan, S., Williams, D., \& Yee, N. (2009). Problematic Internet use and psychosocial well-being among MMO players. Computers in Human Behavior, 25, 1312-1319.

Cole, H., \& Griffiths, M. (2007). Social interactions in massively multiplayer online role-playing gamer. CyberPsychology \& Behavior, 10(4), 575-583.

Diener, E., Emmons, R. A., Larsen, R. J., \& Griffin, S. (1985). The satisfaction with life scale. Journal of Personality Assessment, 49(1), 71-75.

Griffiths, M. D., Davies, M. N., \& Chappell, D. (2004). Demographic factors and playing variables in online computer gaming. CyberPsychology \& Behavior, 7, 479-487.

Hsu, S., Wen, M., \& Wu, M. (2009). Exploring user experiences as predictors of MMORPG addiction. Computer Education, 53, 990-999.

Khazaal, Y., Billieux, J., Thorens, G., Khan, R., Louati, Y., Scarlatti, E., ... Zullino, D. (2008). French Validation of the Internet Addiction Test. CyberPsychology \& Behavior, 11(6), 703-706.

Ko, C. H., Yen, J. Y., Chen, C. C., Chen, S. H., \& Yen, C. F. (2005). Gender differences and related factors affecting online gaming addiction among Taiwanese adolescents. The Journal of Nervous and Mental Disease, 193(4), 273-277.

Kowert, R., Vogelgesang, J., Festl, R., \& Quandt, T. (2015). Psychosocial causes and consequences of online video game play. Computers in Human Behavior, 45, 51-58.

Lemmens, J., Valkenburg, P., \& Peter, J. (2011). Psychosocial causes and consequences of pathological gaming. Computers in Human Behavior, 27, 144-152.

Lo, S., Wang, C., \& Fang, W. (2005). Physical interpersonal relationships and social anxiety among online game players. CyberPsychology \& Behavior, 8(1), 15-20.

Longman, H., O'Connor, E., \& Obst, P. (2009). The effect of social support derived from world of warcraft on negative psychological symptoms. CyberPsychology \& Behavior, 12, 563-566. 
Martončik, M., \& Lokša, J. (2016). Do World of Warcraft (MMORPG) players experience less loneliness and social anxiety in online world (virtual environment) than in real world (offline)?. Computers in Human Behavior, 56, 127-134.

Mentzoni, R., Brunborg, G., Molde, H., Myrseth, H., Skouveroe, K., Hetland, J., \& Pallesen, S. (2011). Problematic video game use: Estimated prevalence and associations with mental and physical health. Cyberpsychology, Behavior, and Social Networking, 14(10), 591-596.

Ng, B., \& Wiemer-Hastings, P. (2005). Addiction to the Internet and online gaming. CyberPsychology \& Behavior, 8(2), 110-113.

Rosenberg, M. (1965). Society and the adolescent self-image. Princeton, NJ: Princeton University Press.

Schweitzer, M. B., \& Paulhan, I. (1990). Manuel pour l'Inventaire d'Anxiété Trait-Etat (Form Y). Laboratoire de Psychologie de la Santé, Université de Bordeaux II.

Scott, J., \& Porter-Amstrong, A. P. (2013). Impact of multiplayer online role-playing games upon the psychosocial well-being of adolescents and young adults: Reviewing the evidence. Psychiatry Journal, 2013, 1-8. Retrieved from http://dx.doi.org/10.1155/2013/464685

Senécal, C. B., Vallerand, R. J., \& Vallières, E. F. (1992). Construction et validation de l'Échelle de la Qualité des Relations Interpersonnelles (EQRI). Revue Européenne de Psychologie Appliquée, 42, 315-322.

Spielberger, C. (1983). Manual for the State-trait anxiety inventory. Palo Alto: Consulting Psychologists Press.

Tejeiro, R. A., \& Bersabé Moran, R. M. (2002). Measuring problem video game playing in adolescents. Addiction, 97(21), 1601-1606.

Tejeiro, R. A., Espada, J. P., Gonzalvez, M. T., \& Christiansen, P. (2016). Psychometric properties of the problem video game playing scale in adults. European Review of Applied Psychology, 66, 9-13.

Vallerand, R. J., \& Richer, S. F. (1998). Construction et validation de l'échelle du sentiment d'appartenance sociale. Revue Européenne de Psychologie Appliquée, 48, 129-137.

Vallières, F., \& Vallerand, R. J. (1990). Traduction et validation Canadienne-Française de l'échelle de l'estime de soi de Rosenberg. International Journal of Psychology, 25, 305-316.

Wan, C., \& Chiou, W. (2006). Why are adolescents addicted to online gaming? An interview study in Taiwan. CyberPsychology \& Behavior, 9(6), 762-766.

Whang, L., Lee, S., \& Chang, G. (2003). Internet over-users' psychological profiles: A behavior sampling analysis on internet addiction. CyberPsychology \& Behavior, 6(2), 143-150.

Williams, D. (2006). Groups and goblins: The social and civic impact of an online game. Journal of Broadcasting \& Electronic Media, 50, 651-681.

Young, K. S. (1998). Caught in the Net. New York: John Willey \& Sons.

Zhong, Z. (2011). The effects of collective MMORPG (Massively Multiplayer Online Role-Playing Games) play on gamers' online and offline social capital. Computers in Human Behavior, 27, 2352-2363. 